\title{
Pomegranate peel as a new low-cost adsorbent for ammonium removal
}

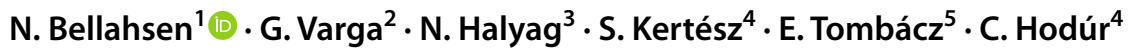

Received: 24 September 2019 / Revised: 6 January 2020 / Accepted: 16 July 2020 / Published online: 29 July 2020

(c) The Author(s) 2020

\begin{abstract}
Since adsorption is one of the best ammonium removal methods, great efforts have been made to identify new low-cost and efficient adsorbents from agricultural waste and by-products due to their abundant availability, low-cost and eco-friendly advantages, in addition to the possibility of recycling ammonium back into agricultural processes. In this study, a series of batch experiments were performed to detect new bio-adsorbents for ammonium ions removal. Among the materials tested, pomegranate peel powder showed a high affinity to adsorb ammonium ions and, furthermore, available information on ammonium adsorption by this biomaterial is still missing from the literature. First, pomegranate peel powder was characterized by the determination of different parameters such as zeta potential, iodine number, Fourier-transform infrared spectroscopy analysis, scanning electron microscopy, particle size distribution and porosity. Then, the impact of various parameters, such as $\mathrm{pH}$, contact time, stirring speed, adsorbent dose and adsorbate concentration in the adsorption process, was investigated. The highest ammonium removal capacity was obtained at $\mathrm{pH}=4$ using $400 \mathrm{mg}$ of pomegranate peel powder and a stirring speed of $150 \mathrm{rpm}$ for an initial concentration of ammonium of $30 \mathrm{mg} / \mathrm{L}$. The system (adsorbent, adsorbate and solution) reached equilibrium after $2 \mathrm{~h}$ and the data fit well with the Langmuir model with a maximum monolayer adsorption capacity of $6.18 \mathrm{mg} / \mathrm{g}$, while kinetics were well described by the pseudo-second-order model. These results introduce pomegranate peel powder as a promising bio-adsorbent to remove and recover ammonium from aqueous solutions.
\end{abstract}

Keywords Adsorption $\cdot$ Agricultural waste and by-products $\cdot$ Nitrogen recovery $\cdot$ Recycling

\section{Introduction}

Nitrogen compounds discharged into water systems have different sources such as municipal and industrial wastewater, leaching waste disposal systems and agricultural runoff. The presence of these nitrogen forms causes serious environmental problems such as eutrophication which leads to a depletion of dissolved oxygen and therefore toxicity to fish and other aquatic organisms (Liu et al. 2010), in addition to a potential risk to human health (Britto and Kronzucker 2002). Moreover, as nitrogen is an indispensable component of fertilizers, its sources are threatened by exhaustion because of the high demand and indiscriminate use (Bhattacharjee et al. 2008); thus, it is important to manage this resource to meet the increased population food demands. Management should include the recovery and reuse of this element as it would reduce water pollution and also provide a new source of nitrogen for agricultural purposes via recycling. Many methods have been developed to remove and recover nitrogen from wastewater, especially ammonium

5 Department of Food Engineering, University of Szeged, Moszkvai krt. 5-7, Szeged 6725, Hungary 
which is the predominant nitrogen source and the most common pollutant encountered in water streams and among these methods adsorption is well known as the most simple and cost-effective process (Karri et al. 2018).

Connected with these environmental challenges, and as a result of the expanding agricultural activities and food production, million tons of agricultural and food waste are disposed worldwide every year. (1.3 billion tonnes of food waste is produced annually according to the Food and Agriculture Organization of the United Nations FAO.) This waste constitutes a serious environmental problem since it is disposed by burning or dumping and this releases a lot of toxic material and pollutants into the environment. Therefore, recycling appears the best option to add economical value to this waste and consequently reduce its burden. However, knowledge of the chemical composition of agricultural waste/by-products (AWBs) is essential for their valorization and the design of novel products. As a lignocellulosic material, AWBs contain large amounts of functional groups (e.g., $-\mathrm{OH},-\mathrm{COH}$ ) which give them an ion exchange capacity and general adsorptive characteristics. Therefore, these biomaterials could be used as adsorbents in their natural and modified forms or even in the production of so-called activated carbons (Karri and Sahu 2017). Recently, various studies have been conducted to check the efficiency of AWBs to remove a variety of pollutants from aqueous solutions, including heavy metals and dyes (Sulyman et al. 2017). However, in spite of the growing interest given to the application of these bio-adsorbents, there are many obstacles concerning deep investigation on adsorption mechanisms and comparative studies under defined conditions to prove their efficiency as alternative adsorbents for wastewater treatment (Worch 2012).

Several AWBs have been studied for ammonium removal from water (Huang et al. 2018, Azreen et al. 2017). The purpose of this study is to investigate the capacity for ammonium ion adsorption by AWBs, as raw materials without any modifications. Bark, wheat husk, compost, wheat bran, banana peel, pomegranate peel and sugar beet pulp were investigated. Among the materials tested, pomegranate peel powder (PPP) exhibited high efficiency in the removal of ammonium ions, and from the relevant literature, this biomaterial holds a large extent of functional groups such as hydroxylic and carboxylic groups. Furthermore, the global world production of pomegranate is estimated to be more than one million tons (Sheikh 2006) and a large proportion of this production is processed for juice, jams and other industries generating a huge amount of valueless pomegranate peel causing a problem of waste disposal and management (Talekar et al. 2018; Demiray et al. 2018). In addition, because of its biodegradability the ammonium-loaded PPP can be applied directly onto agricultural fields as a slowrelease fertilizer or as bio-compost to improve soil fertility. Therefore, analytical study will focus on this biomaterial to determine the parameters influencing the adsorption process and to identify isotherms and kinetics in order to obtain insight into the process mechanisms and characteristics.

Finally, adsorption of nutrients-including nitrogen compounds - using food residues or AWBs appears to be a creative technology based in the " 3 R" principle: Reduce, Reuse and Recycle. This process will solve the problems discussed above since it will not only reduce the burden of reactive nitrogen production and waste disposal, but also add value to this waste and, more importantly, purify water and recycle nutrients to mitigate their exhaustion for a sustainable environment (Fig. 1).

The research has been carried out at the department of process engineering, Faculty of engineering, University of Szeged, Hungary, in 2019.

\section{Materials and methods}

\section{Adsorbents preparation}

Seven AWBs were collected, including pomegranate peel, banana peel, wheat husk, compost, bark, wheat bran and sugar beet pulp. Samples were cut into small pieces and washed with distilled water several times to remove dust and impurities; then they were oven dried at $110{ }^{\circ} \mathrm{C}$ for two hours. Finally, dried materials were crushed and grounded to desired particle size $(<250 \mu \mathrm{m})$ and the final material was a powder used in raw form for adsorption experiments.

\section{Preparation of stock solution}

Calculated weights of ammonium chloride salt, $\mathrm{NH}_{4} \mathrm{Cl}$, were dissolved in distilled water to obtain desired ammonium concentrations $\left[\mathrm{NH}_{4}^{+}\right]$. The initial $\mathrm{pH}$ value of the solution was adjusted using dilute solutions of $0.1 \mathrm{M}$ of sodium hydroxide $\mathrm{NaOH}$ or hydrochloric acid $\mathrm{HCl}$.

\section{Screening experiments}

The screening experiments were performed according to the batch method where 100 milligrams of each sample was shaken at $100 \mathrm{rpm}$ and at room temperature with $60 \mathrm{ml}$ of $\mathrm{NH}_{4} \mathrm{Cl}$ solution containing [30 mg/L] of $\mathrm{NH}_{4}{ }^{+}$. To compare the efficiency of the materials tested, the variation of $\mathrm{NH}_{4}^{+}$ 
Fig. 1 The aim of the adsorption study using AWBs to recycle nutrients

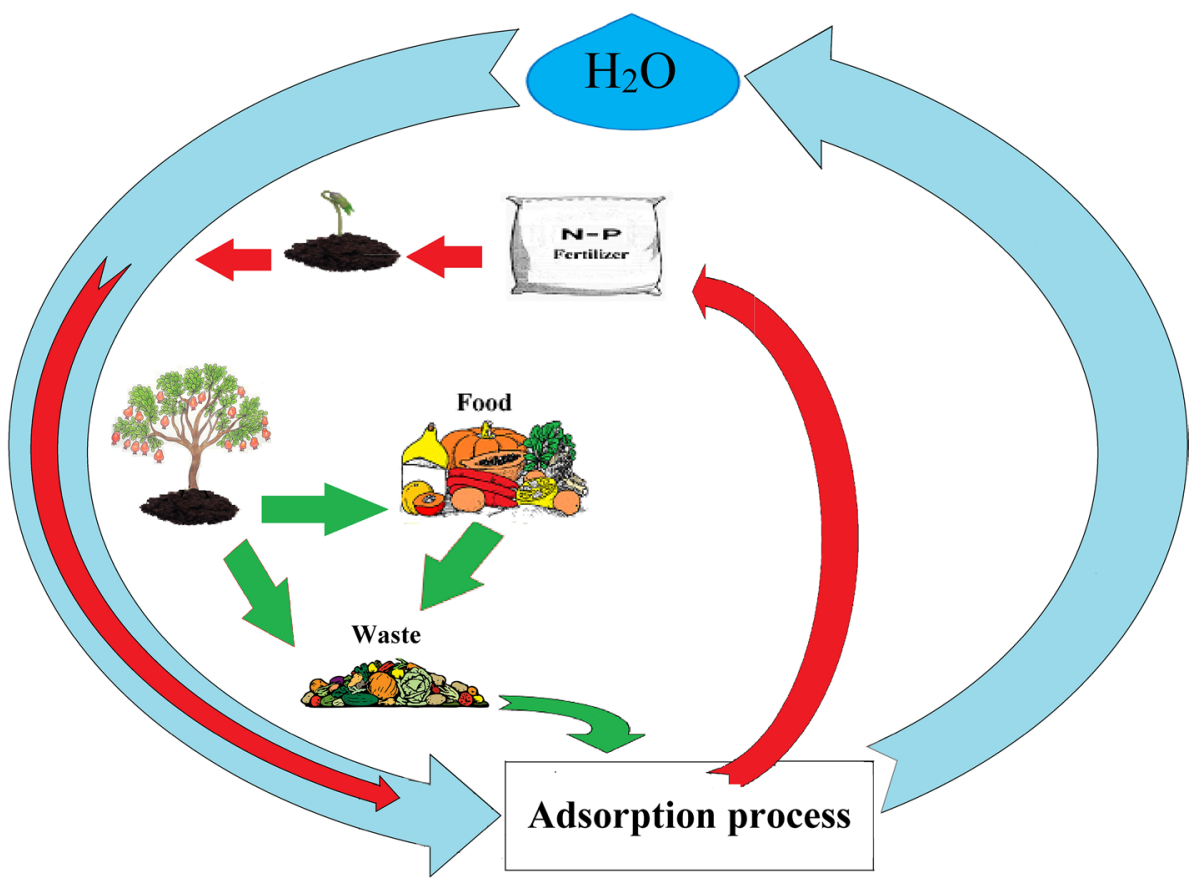

concentration was measured continuously until it becomes stable. For measurements, solutions were filtered using $0.45 \mu \mathrm{m}$ microporous membrane filters and $\mathrm{NH}_{4}{ }^{+}$concentration in each filtrate was analyzed using Merck Spectrophotometer Spectroquant Nova 60. The ammonium removal rate can be calculated as shown in Eq. (1):

$\%$ Removal $=\frac{c_{f}-c_{i}}{c_{i}} * 100$

where $c_{i}$ and $c_{f}$ are the initial and final nitrogen concentrations, respectively.

\section{Characterization of adsorbents}

\section{a. Zeta potential test}

Zeta potential is the only measurable parameter of an electric double layer, and it is widely used for the quantification of the sign and magnitude of the particle charge state. Zeta potential of the tested adsorbents was investigated by a zetasizer device (Nano ZS, Malvern) where $10 \mathrm{mg}$ of each sample was added to $20 \mathrm{~mL}$ of $\mathrm{NH}_{4} \mathrm{Cl}$ solution at different $\mathrm{pH}$ and ammonium concentrations. b. Iodine number

Pore structure of materials tested was quantified by standard determination of the iodine adsorption number (Bunnag and Yamani 2006) where $25 \mathrm{~mL}$ of iodine solution was put in a flask with the sample (around $0.1 \mathrm{~g}$ ) and mixed for $1 \mathrm{~min}$. After that, it was centrifuged for $3 \mathrm{~min}$. Finally, $10 \mathrm{~mL}$ of the centrifuged solution was used in a titration with a sodium thiosulfate solution. The iodine number is calculated as illustrated in Eq. (2):

Iodine number $=v\left(T_{i}-T_{f}\right) c_{i} \frac{M_{i}}{\left(T_{i} \cdot g\right)}$

where $v$ : volume of iodine; $T_{i}(\mathrm{ml})$ : $\left(\mathrm{Na}_{2} \mathrm{~S}_{2} \mathrm{O}_{3} \cdot 5 \mathrm{H}_{2} \mathrm{O}\right)$ solution used for titration of $10 \mathrm{ml}$ iodine solution; $T_{f}(\mathrm{ml})$ : $\left(\mathrm{Na}_{2} \mathrm{~S}_{2} \mathrm{O}_{3} \cdot 5 \mathrm{H}_{2} \mathrm{O}\right)$ solution used for titration of $10 \mathrm{ml}$ filtrate solution; $g$ : weight of the sample in grams; $M_{i}$ : molar mass of iodine; and $c_{i}$ : iodine concentration.

c. Particle size distribution and porosity

The particle size distribution and the calculated geometric specific surface area of PPP were determined using Horiba LA-950V2 type laser particle size analyzer in dry mode. 
From the measured data, the computer calculated the particle size distribution according to the Fraunhofer theory. The measurement range of the analyzer is between $10 \mathrm{~nm}$ and $3 \mathrm{~mm}$.

The porosity of PPP was determined using Micromeritics' AutoPore IV 9500 Series, which characterizes a material's porosity by applying various levels of pressure to a sample immersed in mercury. This method is called mercury porosimetry or often "mercury intrusion."

d. FTIR- ATR analysis and scanning electron microscope.

The instrument for recording the spectra was a Bio-Rad Digilab Division FTS-65A/896 FTIR spectrophotometer with $4 \mathrm{~cm}^{-1}$ resolution. The $4000-400 \mathrm{~cm}^{-1}$ wavenumber range was recorded. A total of 256 scans were collected for each spectrum. In addition to the spectra of each sample, single reflection diamond ATR accessory measurements were taken.

Scanning electron microscope (SEM) was also used for imaging the microstructure of PPP before and after $\mathrm{NH}_{4}^{+}$ adsorption to check the variation in its surface morphology.

\section{Batch adsorption experiments using PPP}

Based on the results of screening experiments, PPP was selected to study the equilibrium characteristics of $\mathrm{NH}_{4}{ }^{+}$ adsorption. The first series of experiments were carried out to assess the effects of influencing parameters, such as initial

Table 1 Removal rates of $\mathrm{NH}_{4}{ }^{+}$removal by the materials tested

\begin{tabular}{lc}
\hline Adsorbents & Removal rate \% \\
\hline Compost & $-20 \%$ \\
Wheat bran & 6.7 \\
Wheat Husk & 6.7 \\
PPP & 36.7 \\
Sugar beet pulp & 6.7 \\
Bark & 4.2 \\
Banana peel & -6 \\
\hline
\end{tabular}

$\mathrm{NH}_{4}{ }^{+}$concentration, $\mathrm{pH}$, adsorbent dose, stirring speed and contact time.

The adsorbed amount of ammonium ion $(\mathrm{mg} / \mathrm{g})$ was calculated as shown in Eq. (3):

$q_{e}=\left(c_{i}-c_{e}\right) \frac{V}{M}$

where $c_{i}(\mathrm{mg} / \mathrm{L})$ and $c_{e}(\mathrm{mg} / \mathrm{L})$ are the initial and equilibrium concentrations of $\mathrm{NH}_{4}{ }^{+}$in the solution, respectively. $V(L)$ is the solution volume and $M(g)$ is the mass of adsorbent.

For isotherm and kinetics modeling, data were fitted to the existing models, and the best-fit models for both isotherm and kinetic studies were selected based on the highest coefficient correlation $\left(R^{2}\right)$ and correspondence with calculated parameters.

\section{Results and discussion}

\section{Screening tests}

Most of the materials tested show low efficiency in adsorption of $\mathrm{NH}_{4}{ }^{+}$, as the removal rates with wheat bran, wheat husk, sugar beet pulp and bark were only $6.7 \%$. Moreover, removal rates using compost and banana peel were negative because these biomaterials release nitrogen which combines with protons present in solution to form ammonium. However, the removal using PPP was $36.7 \%$ effective, leading us to focus on this potential bio-adsorbent (Table 1).

\section{Characterization results}

\section{a. Zeta potential}

The surface properties of PPP were investigated by zeta potential measurements, as illustrated in Fig. 2a, b; PPP surface groups are negatively charged in the studied range of $\mathrm{pH}$ and solution concentrations.

The value of zeta potential decreases with the increase in $\mathrm{pH}$ resulting in a higher negative charge on the PPP surface (Fig. 2a). The negatively charged surface contributes to
Fig. 2 a Zeta potential of $\mathrm{PPP}$ as a function of $\mathrm{pH}$ in [10 $\mathrm{mmol} / \mathrm{L}]$ of $\mathrm{NH}_{4} \mathrm{Cl}$ solution, b zeta potential of PPP as a function of $\mathrm{NH}_{4} \mathrm{Cl}$ concentration $(\mathrm{mmol} / \mathrm{L})$
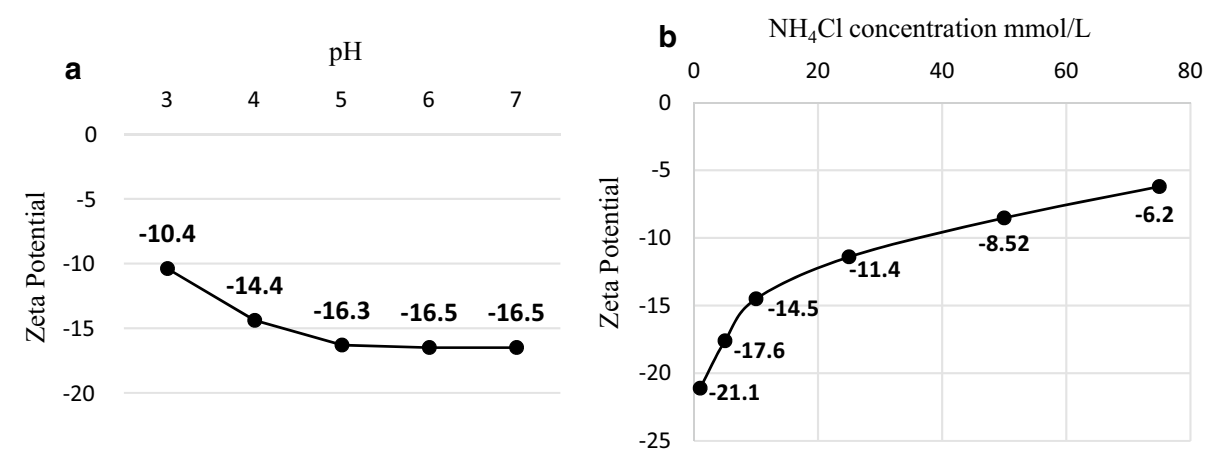
Table 2 Zeta potential of materials tested in $10 \mathrm{mmol} / \mathrm{L}$ $\mathrm{NH}_{4} \mathrm{Cl}$ at $\mathrm{pH} 5$

\begin{tabular}{ll}
\hline Adsorbents & Zeta potential \\
\hline Compost & -20.8 \\
Bark & -19.3 \\
Sugar bagasse & -17.1 \\
Banana & -16.1 \\
PPP & -15.6 \\
Wheat Bran & -14.3 \\
Husk & -11.5 \\
\hline
\end{tabular}

Table 3 Iodine number of materials tested and zeolite

\begin{tabular}{lc}
\hline Adsorbent & Iodine number \\
\hline Banana peel & 233 \\
Compost & 115 \\
Bark & 98 \\
Wheat husk & 70 \\
Wheat bran & 70 \\
Sugar beet pulp & 70 \\
PPP & 595 \\
Zeolites & $400-900$ \\
\hline
\end{tabular}

the ability of functional groups to adsorb positively charged ions since it represents the driving force for electrostatic interaction with $\mathrm{NH}_{4}{ }^{+}$(Cui et al. 2016). In addition, Fig. $2 \mathrm{~b}$ shows that zeta potential increases with increasing $\mathrm{NH}_{4} \mathrm{Cl}$ concentration due to the charge screening of electrolytes and the saturation of available negatively charged surface sites (López-Ramón et al. 2003).
Furthermore, Table 2 shows that other materials have higher negatively charged surfaces than PPP but lower adsorption capacities for $\mathrm{NH}_{4}{ }^{+}$, suggesting that the electrostatic interaction is not the only adsorption mechanism involved and there is another mechanism which could be an ion exchange property derived from functional groups present on PPP surface (Ben-ali et al. 2017).

b. Iodine number

Iodine number measurement gives an indication of the pore volume available in the material of interest. Among the materials tested, PPP has the highest value $(595 \mathrm{mg} / \mathrm{g}$ ) and it is in the range of zeolite (the specific adsorbent for ammonium) (Table 3).

\section{c. Particle size distribution and porosity}

The particle size of the adsorbent is an important parameter indicating its capacity and its surface accessibility (Worch 2012). PPP used in this study had a specific surface area of $101,600 \mathrm{~m}^{2} / \mathrm{m}^{3}$, and a particle size ranged from approximately $10 \mu \mathrm{m}$ to $750 \mu \mathrm{m}$ (Fig. 3a). When particle size decreased, the specific surface area increased, leading to an improvement in bioavailability and absorptivity due to fast dissolution of active functional ingredients (Zhong et al. 2016). However, using adsorbents with very fine pores to remove large adsorbate molecules restricts the extent of adsorption by size exclusion (Worch 2012). Likewise, the porosity of a material affects its physical properties and subsequently its behavior in its surrounding environment, especially adsorption ability. Porosity of PPP was $22.89 \%$,

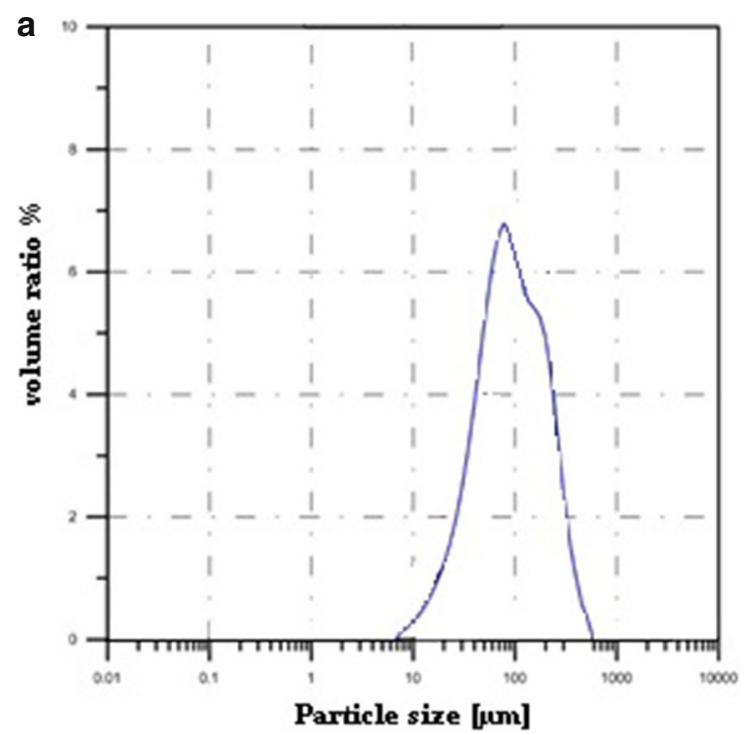

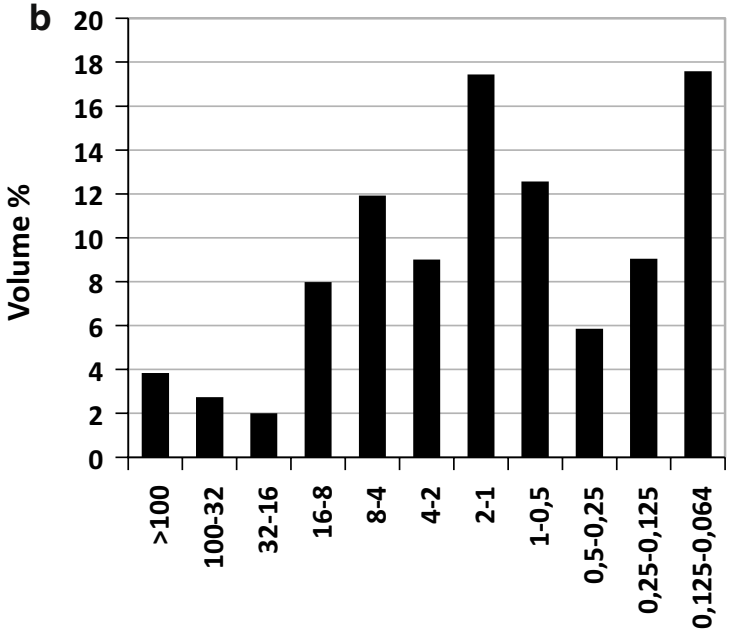

radius $(\mu \mathrm{m})$

Fig. 3 a Graph of particle size distribution of PPP used, b pore size distribution chart of PPP used 
whereas its pore size distributions and total pore volume are shown in Fig. $3 b$.

\section{d. Properties of PPP}

It is known from the relevant literature that pomegranate peel represents 28 to $32 \%$ of the total weight of the fruit. Chemical composition may affect the adsorbate/ adsorbent interaction and represents an interesting feature of AWBs, especially the nature of functional groups available on their surface since they have the ability to bind pollutants to some extent through ionic interactions (Pagnanelli et al. 2003). The main PPP surface functional groups are hydroxylic and carboxylic groups derived from carboxylic acid, phenol or alcohols, ketone, aldehyde, ethers and esters (Ben-ali et al. 2017). Recently, a lot of studies have been done using PPP to remove $\mathrm{Cr}(\mathrm{VI})$, $\mathrm{Ni}(\mathrm{II}), \mathrm{Pb}(\mathrm{II}), \mathrm{Cu}(\mathrm{II})$ and Congo red from water samples (El Nemr 2009; Bhatnagar and Minocha 2010; Alam et al. 2012; El-Ashtoukhy et al. 2008; Ghaedi et al. 2012).

\section{e. FTIR-ATR analysis and SEM results}

The FTIR spectra of PPP before and after adsorption of $\mathrm{NH}_{4}{ }^{+}$were used to assess the changes in the functional groups present on its surface. As illustrated in Fig. 4a, the FTIR spectra of PPP display a number of absorption peaks ranging from 400 to $4000 \mathrm{~cm}^{-1}$, indicating the complex nature of the studied adsorbent. Two significant differences can be seen on spectrum of used material compared to the fresh material; two new well-separated peaks appeared at 1370 and $1656 \mathrm{~cm}^{-1}$ belonging to the $\nu_{4^{-}}$and $\nu_{2}$-type vibrations of $\mathrm{NH}_{4}{ }^{+}$(De Waal et al. 1990). In general, the observed variation of major peaks indicates the involvement of corresponding groups in the binding of $\mathrm{NH}_{4}^{+}$to PPP surface.

SEM micrographs showed the surface morphology of PPP before and after $\mathrm{NH}_{4}{ }^{+}$uptake at the same magnification power $(50,000 \times)$. The surface texture of PPP before $\mathrm{NH}_{4}{ }^{+}$uptake was flat and smooth (Fig. 4b); however, this surface becomes more rough and uneven after $\mathrm{NH}_{4}{ }^{+}$uptake (Fig. 4c).
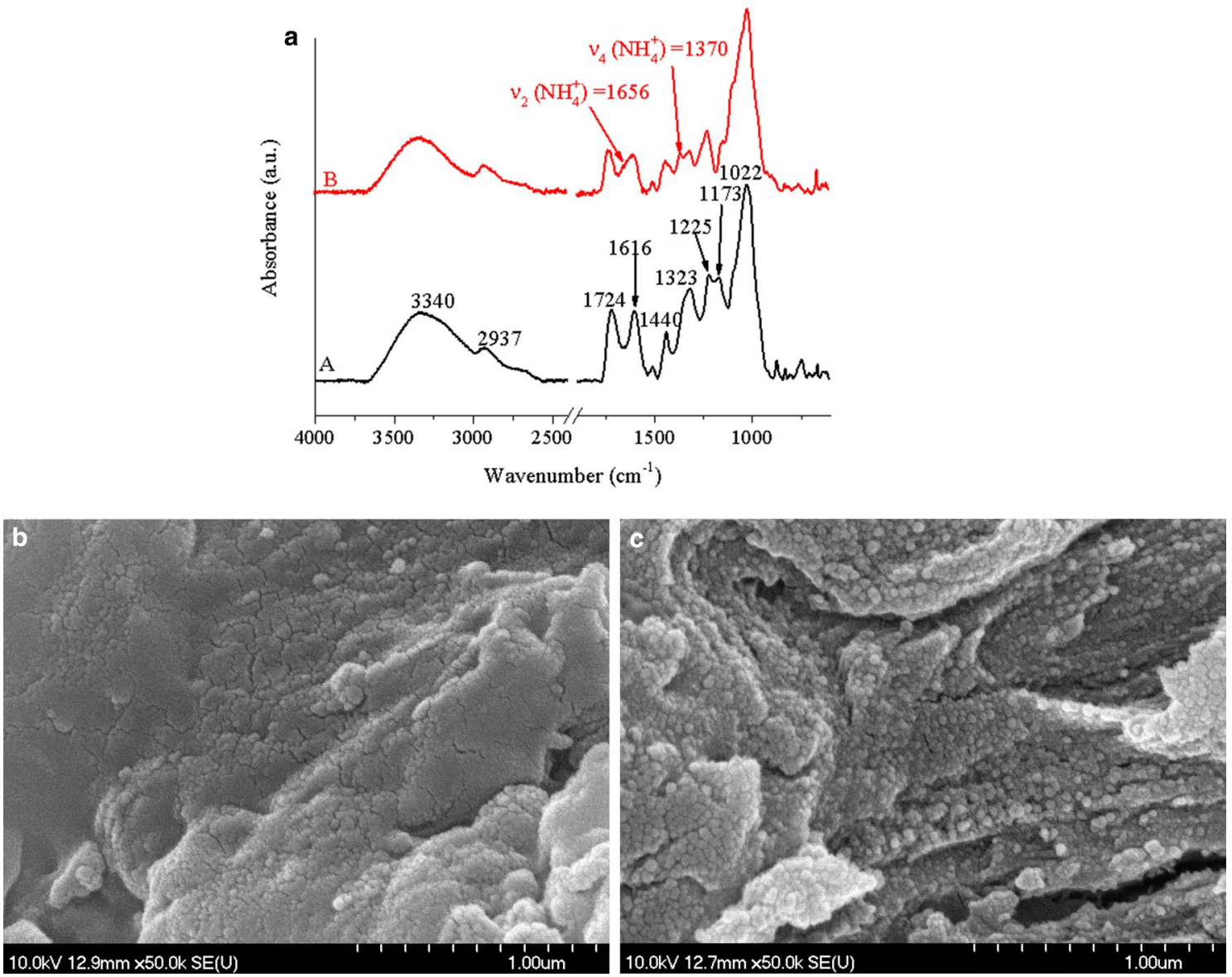

Fig. 4 a FTIR- ATR analysis of PPP before (A) and after adsorption of $\mathrm{NH}_{4}^{+}$(B), b SEM of PPP before $\mathrm{NH}_{4}{ }^{+}$uptake, $\mathbf{c} \mathrm{SEM}_{\text {of }} \mathrm{PPP} \mathrm{NH}_{4}{ }^{+}$ uptake 
Fig. 5 a Effect of initial $\mathrm{NH}_{4}^{+}$ concentration, $\mathbf{b}$ effect of $\mathrm{pH}, \mathbf{c}$ effect of adsorbent dose, $\mathbf{d}$ effect of stirring speed, e effect of contact time $\left(\left[\mathrm{NH}_{4}^{+}\right]: 30 \mathrm{mg} / \mathrm{L}\right.$, adsorbent dose: $100 \mathrm{mg}, \mathrm{pH}: 4$, stirring speed: $100 \mathrm{rpm}$, contact time: $120 \mathrm{~min}$ )
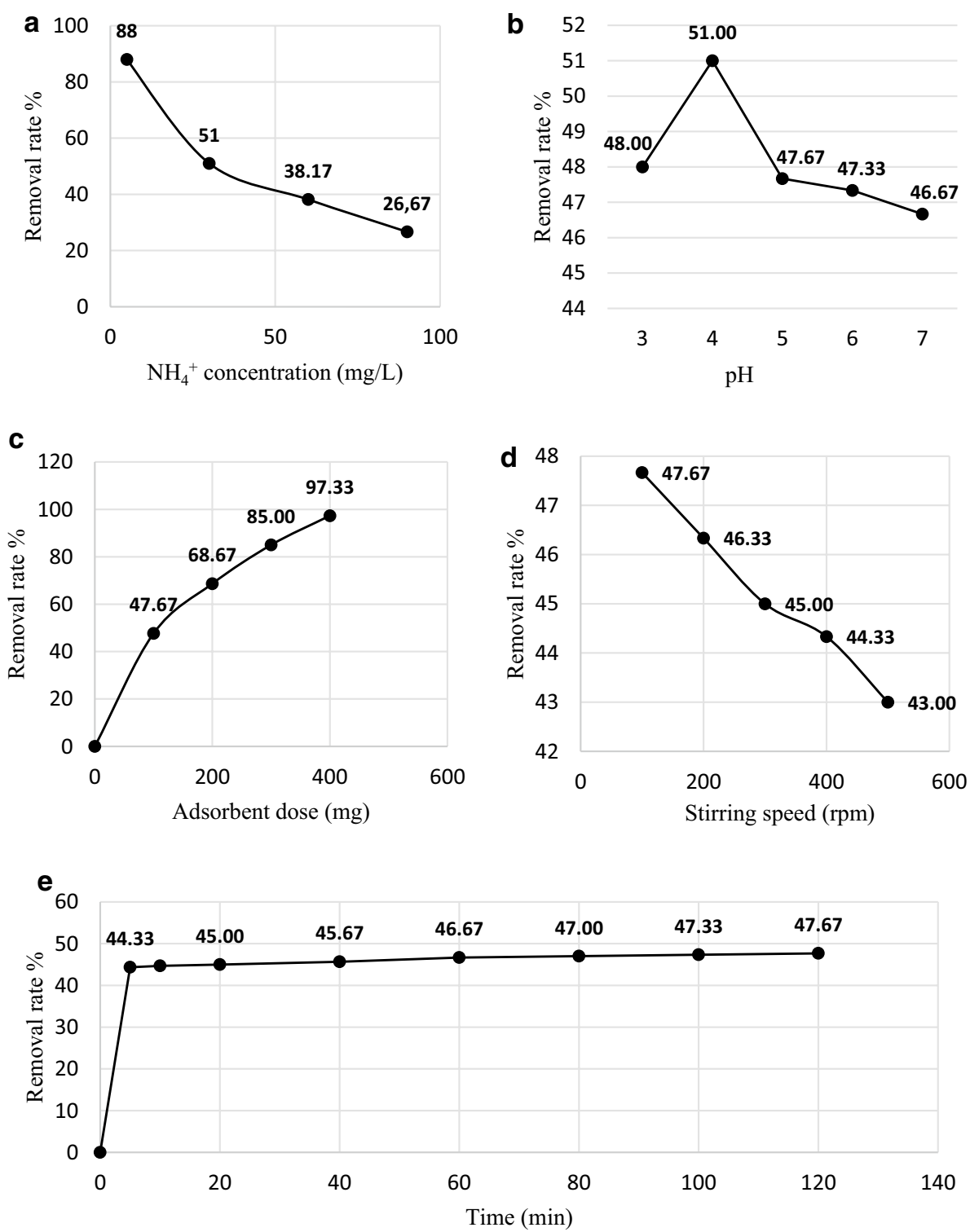

\section{Batch adsorption results}

\section{a. Effect of initial ammonium concentration}

The effect of initial concentration on the removal of $\mathrm{NH}_{4}^{+}$ by PPP was studied employing different initial $\mathrm{NH}_{4}{ }^{+}$concentrations $(5,30,60$, and $90 \mathrm{mg} / \mathrm{L})$ at room temperature. It is clear from Fig. 5a that the removal rate decreased with increasing initial $\mathrm{NH}_{4}{ }^{+}$concentration. Maximum removal was $88 \%$ at an initial concentration of $5 \mathrm{mg} / \mathrm{L}$, indicating a high affinity of the PPP surface for $\mathrm{NH}_{4}{ }^{+}$. Moreover, low concentration allows more time for $\mathrm{NH}_{4}{ }^{+}$to bind to the adsorption sites with a slower mass transfer coefficient, while increasing $\mathrm{NH}_{4}{ }^{+}$concentration leads to an increase in the driving force and therefore these adsorption sites are occupied and the PPP surface is saturated which in turn leads to a fast breakpoint. However, the amount of $\mathrm{NH}_{4}{ }^{+}$ adsorbed per unit mass of adsorbent ( $\mathrm{mg} / \mathrm{g}$ ) decreased due to its low concentration in solution. Similar results were found for ammonium recovery by zeolite (Kotoulas et al. 2019).

\section{b. Effect of $\mathrm{pH}$}

To study the effect of $\mathrm{pH}$, experiments were performed

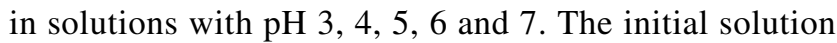
$\mathrm{pH}$ plays a critical role in adsorption processes as it affects 
both adsorbate and adsorbent characteristics and behaviors, especially in adsorption involving charge-charge interactions (Myers 1999). In acidic solutions, more protons, $\mathrm{H}^{+}$, are present, which compete effectively with $\mathrm{NH}_{4}{ }^{+}$cations; however, this study shows a negligible effect of $\mathrm{pH}$, with maximum removal at $\mathrm{pH} 4$ (51\%) (Fig. 5b). The $\mathrm{pH}$ effect could be explained by the existence of a large range of different functional groups (carboxylic and hydroxylic groups) in PPP surface leading to a large number of possible interactions with $\mathrm{NH}_{4}{ }^{+}$and other solutes present in the solution; therefore, the influence of the $\mathrm{pH}$ value on the adsorbate properties and adsorbent surface charge is negligible. These results coincide with results of zeta potential measurements that showed negative surface charge of PPP for all $\mathrm{pH}$ ranges studied; therefore, this $\mathrm{pH}$ independence presents another advantage of using PPP as an adsorbent of ammonium. The results obtained in this study are in a good agreement with those reported in previous study using PPP for heavy metals removal (Rao and Rehman 2010).

\section{c. Effect of adsorbent dose}

The effect of adsorbent dose was studied by varying the used mass of PPP from $100 \mathrm{mg}$ to $400 \mathrm{mg}$ and keeping other parameters constants. Increasing PPP dose shows a remarkable increase in the removal rate of $\mathrm{NH}_{4}^{+}$(from $47.67 \%$ for $100 \mathrm{mg}$ to $97.33 \%$ for $400 \mathrm{mg}$ ) because increasing the amount of adsorbent introduced into the solution provides larger adsorption surface and therefore more available active binding sites for $\mathrm{NH}_{4}^{+}$(Ismail and Hameed 2014) (Fig. 5c).

\section{d. Effect of stirring rate}

Certainly, stirring rate is an influencing parameter in the adsorption mechanism since it is the physical driving force of the process. Figure 5d shows the removal rate of $\mathrm{NH}_{4}{ }^{+}$ by PPP at different stirring speeds (from 100 to $400 \mathrm{rpm}$ ).
The maximum removal rate was $47.67 \%$ at $100 \mathrm{rpm}$. The adsorption capacity of PPP decreased slightly as the stirring rate increased. This reduction is due to the turbulence produced by high rotation speeds which led the adsorbentbound ammonium ions to be released again, and the ions did not have enough time to meet the adsorbent surface at higher speeds and, as a result, the adsorption mechanism was perturbed (Fauzia et al. 2015).

\section{e. Effect of contact time}

The adsorption of contaminants from liquid solution into solid surface is usually divided on three phases (Sulyman et al. 2017). The time progress for $\mathrm{NH}_{4}{ }^{+}$adsorption by PPP is shown in Fig. 5e, and it can be divided on three phases starting with the initial phase which is rapid and characterized by high removal rates ( $44 \%$ within $5 \mathrm{~min}$ ) due to the initially larger surface area and availability of free active sites, mainly carboxylic $\mathrm{COO}^{-}$and hydroxylic $\mathrm{OH}^{-}$groups. Then, as the contact time increases, the rate gradually becomes slower (from 44.67 to $47.33 \%$ ) because of the slow passage of $\mathrm{NH}_{4}^{+}$ into the internal structure of PPP. This phase is known as the intermediate phase. After $120 \mathrm{~min}$, the removal rate reached a constant value (47.67\%) where no more $\mathrm{NH}_{4}{ }^{+}$was removed from the solution because of the saturation of free active sites and the system reached equilibrium.

\section{Adsorption isotherm}

The adsorption isotherm is a curve describing the interaction adsorbent/adsorbate at a constant temperature by relating the equilibrium concentration of the solute on the surface of an adsorbent $\left(\mathrm{q}_{\mathrm{e}}\right)$ to the concentration of the solute in the liquid (Ce) with which it is in contact (Ramasamy and Krishnamoorthy 2015). This isotherm may be affected by the properties of the adsorption system components and should take into consideration several parameters (Myers 1999). The capacity of PPP to adsorb $\mathrm{NH}_{4}{ }^{+}$was evaluated through a series of batch
Fig. 6 a Adsorption isotherm of $\mathrm{NH}_{4}{ }^{+}$by PPP, b Langmuir isotherm model of $\mathrm{NH}_{4}^{+}$adsorption by PPP
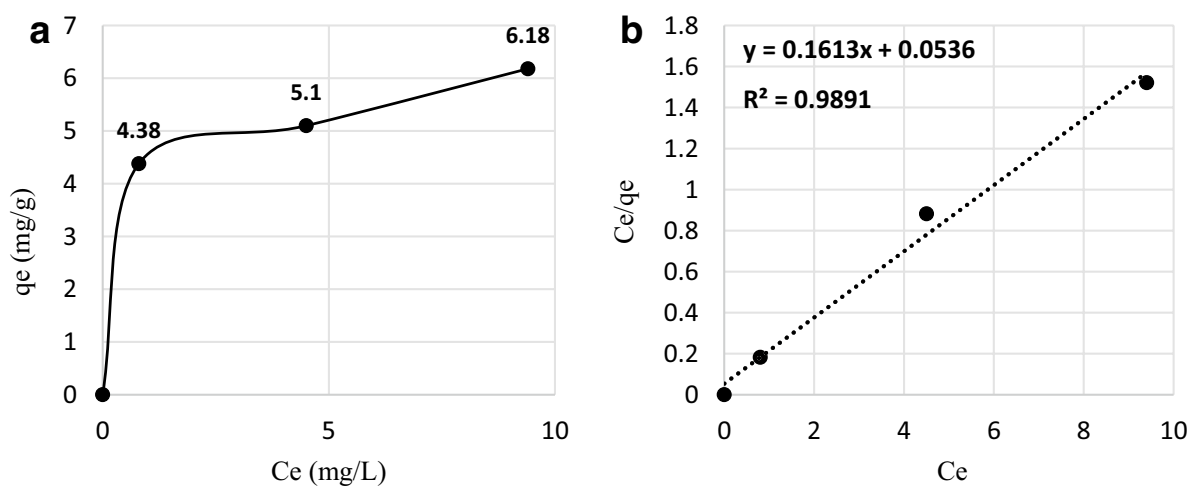
adsorption experiments using different doses of PPP and a constant initial $\mathrm{NH}_{4}{ }^{+}$concentration and temperature (Fig. 6a).

To select the isotherm model that adequately describes the adsorption mechanism, experimental adsorption data have to be combined with mathematical modeling (Xu et al. 2013). Among the models tested to describe the adsorption of $\mathrm{NH}_{4}{ }^{+}$ by PPP, the Langmuir isotherm fits best with the obtained experimental adsorption data (Fig. 6b). This model assumes that the adsorption process is localized and controlled by monolayer coverage of the adsorbent surface where all adsorption sites possess equal affinity for the adsorbate (Myers 1999). Furthermore, intermolecular attractive forces diminish rapidly with distance, in addition to the absence of interaction between adsorbed molecules on neighboring sites (Gimbert et al. 2008).

Equations (4) and (5) present the Langmuir equation and its linearized form, respectively:

$Q=\frac{\mathrm{Qm} b \mathrm{Ce}}{1+b \mathrm{Ce}}$
$\frac{\mathrm{Ce}}{\mathrm{Qe}}=\frac{\mathrm{Ce}}{\mathrm{Qm}}+\frac{1}{\mathrm{Qm} b}$

where Qm (mg/g) is the maximum ammonium uptake, $b(\mathrm{~L} /$ $\mathrm{mg})$ is the Langmuir adsorption constant, Qe ( $\mathrm{mg} / \mathrm{g})$ is the equilibrium ammonium uptake and $\mathrm{Ce}(\mathrm{mg} / \mathrm{L})$ is the equilibrium concentration.

The constant $b$ for the Langmuir model can be obtained from the slope and intercept of a graph $\mathrm{Ce} / \mathrm{Qe}$ against $\mathrm{Ce}$. In this case, $b=3.01$ and it presents an index of affinity between the adsorbent and adsorbate since it is related to the adsorption energy (Dawodu and Akpomie 2014).

The parameter $R_{\mathrm{L}}$ that is recognized as the separation factor can be calculated as shown in Eq. (6):

$\mathrm{RL}=1 /(1+b c i)$

The value of RL obtained is 0.01 which is very low and indicates that the adsorption of $\mathrm{NH}_{4}{ }^{+}$into PPP is favorable and could even be irreversible (Foo and Hameed 2010).
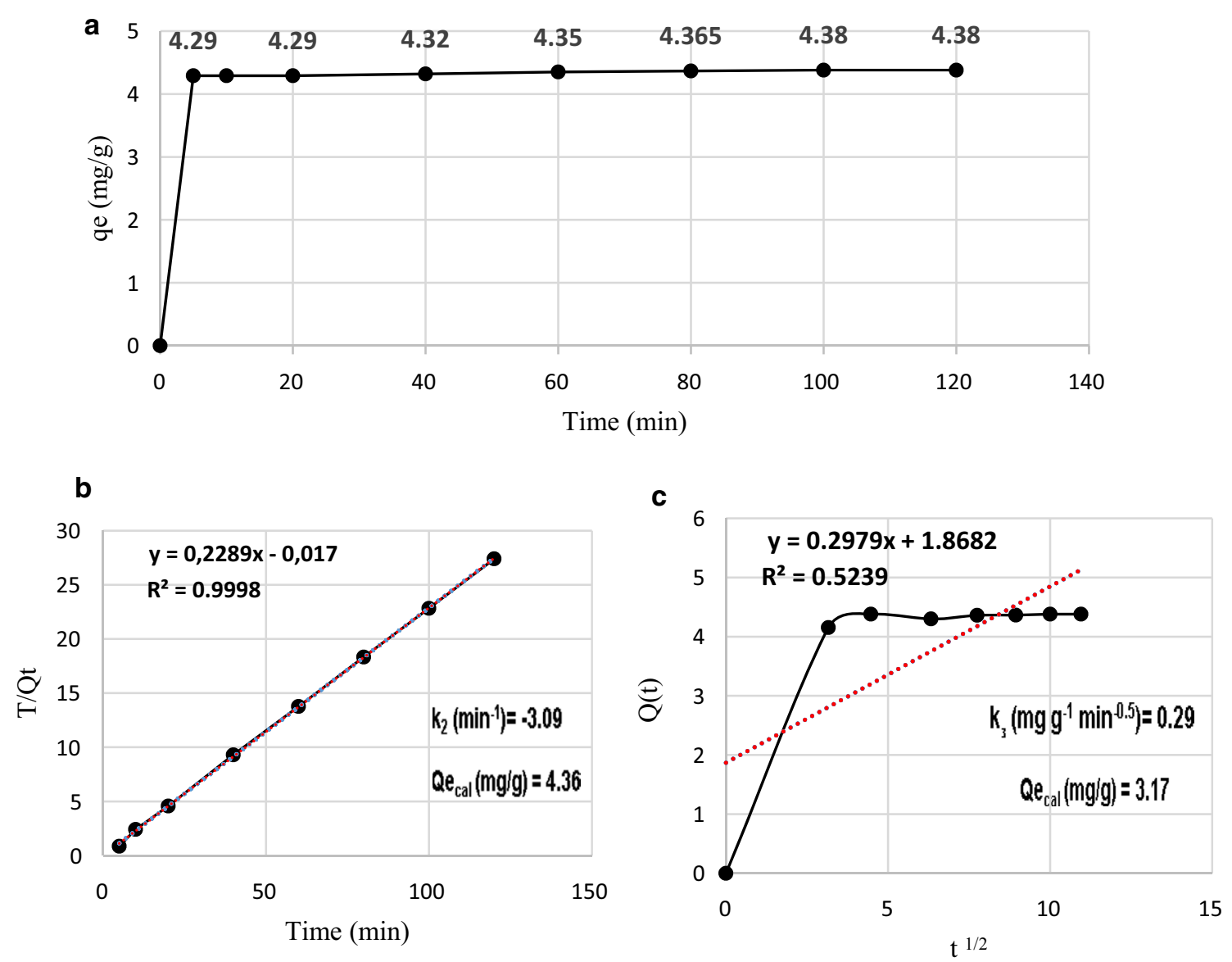

Fig. 7 a Kinetics curve of $\mathrm{NH}_{4}{ }^{+}$adsorption by PPP, b pseudo-second-order kinetic model, $\mathbf{c}$ intra-particle diffusion model (400 mg PPP, $30 \mathrm{mg} / \mathrm{L}\left(\mathrm{NH}_{4}^{+}\right), \mathrm{pH} 4$, stirring speed 150) 


\section{Adsorption kinetics}

Adsorption kinetics present the time progress of the adsorption process and describes the mass transfer from solution to the adsorption sites, and thus, it determines the time required to reach the state of equilibrium. An understanding of adsorption kinetics arises from identifying governing mass transfer mechanisms and its characteristic parameters (Worch 2012). In order to study the kinetics of $\mathrm{NH}_{4}{ }^{+}$adsorption by PPP, a change in $\mathrm{NH}_{4}{ }^{+}$concentration over time was followed and measured by taking samples at defined time intervals. The resulting kinetic curve is shown in Fig. 7a. This curve provides the data for a fitting procedure with existing kinetic models. The adsorption mechanisms of $\mathrm{NH}_{4}{ }^{+}$by PPP were evaluated using two kinetic models (pseudo-second-order and intra-particle diffusion model). As in isotherm modeling, selecting the best-fit kinetic model is based on the value of the linear regression correlation coefficient $\left(R^{2}\right)$ and the calculated equilibrium adsorption capacity $\left(\mathrm{Qe}_{\mathrm{cal}}\right)$.

\section{a. Pseudo-second order}

This model is represented by a plot of ( $t / \mathrm{Q} t)$ against $(t)$ (Ho and Mckay 1999). Its equation and linearized form are shown in Eqs. (7) and (8), respectively.

$\frac{\mathrm{dQt}}{\mathrm{d} t}=k(\mathrm{Qe}-\mathrm{Qt})$

$\frac{t}{\mathrm{Qt}}=\left(\frac{1}{k \mathrm{Qe}}\right)+\left(\frac{1}{\mathrm{Qe}}\right) t$

This model fits well with kinetics data of $\mathrm{NH}_{4}{ }^{+}$adsorption by PPP according to values of coefficient of correlation $R^{2}$ and $\mathrm{Qe}_{\text {cal }}$ (Fig. 7b). This model assumes that the adsorption process is governed by chemical sorption and involves sharing and exchange of electrons between the adsorbent and adsorbate (Jellali et al. 2011).

\section{b. Intra-particle diffusion}

This model is a linear plot of (Qt) versus $(\sqrt{ } t)$, and it is employed to identify the governing step in the adsorption process. The equation of the intra-particle diffusion model and its linearized form are shown in Eq. (9).

$Q t=k \sqrt{ } t$

As illustrated in Fig. 7c, the linear plot is not passing through the origin with a low value of correlation factor $R^{2}$, indicating that intra-particle diffusion is not the only rate limiting step involved in the adsorption of $\mathrm{NH}_{4}{ }^{+}$by PPP. Therefore, the process mechanism occurs in several steps, starting with an instantaneous adsorption stage, then intraparticle diffusion into pores and ends with the final equilibrium step (Gu et al. 2011).

\section{Conclusion}

The ability of seven AWBs including bark, wheat husk, compost, wheat bran, banana peel, pomegranate peel and sugar beet pulp as a potential low-cost adsorbent for ammonium removal was investigated in this study. Among materials tested, the results of adsorption of ammonium by PPP showed that a dose of $400 \mathrm{mg}$ of this biomaterial could achieve $97 \%$ ammonium removal at $\mathrm{pH}=4$ with a stirring speed of $100 \mathrm{rpm}$, making this valueless waste a promising alternative to the usual expensive commercial adsorbents, while other tested materials showed low or even negative efficiency. This study also demonstrates that contact time, initial concentration of $\mathrm{NH}_{4}{ }^{+}$and PPP dose used are factors with the greatest effects on adsorption of ammonium by PPP. However, a study of the effect of interfering ions is required to better understand the adsorption mechanism through an investigation in multi-solute solutions or even real wastewater because single-solute adsorption systems helps only to understand general aspects of adsorption without considering other influencing parameters. Moreover, investigating the reusability of ammonium-loaded PPP as a possible biofertilizer or even bio-compost presents a pivotal issue since it will open new options in sustainability.

Acknowledgements Open access funding provided by University of Szeged. The authors are grateful for the financial support provided by the project Hungarian Scientific Research Fund (NKFI contract number K115691) and EFOP-3.6.2- 16-2017-00010 - RING 2017. Project no. TÉT_16-1-2016-0138 has been implemented with the support provided from the National Research, Development and Innovation Fund of Hungary, financed under the TÉT_16 funding scheme.

\section{Compliance with ethical standards}

Conflict of interest The authors declare that they have no conflicts of interest.

Open Access This article is licensed under a Creative Commons Attribution 4.0 International License, which permits use, sharing, adaptation, distribution and reproduction in any medium or format, as long as you give appropriate credit to the original author(s) and the source, provide a link to the Creative Commons licence, and indicate if changes were made. The images or other third party material in this article are included in the article's Creative Commons licence, unless indicated otherwise in a credit line to the material. If material is not included in 
the article's Creative Commons licence and your intended use is not permitted by statutory regulation or exceeds the permitted use, you will need to obtain permission directly from the copyright holder. To view a copy of this licence, visit http://creativecommons.org/licenses/by/4.0/.

\section{References}

Alam M, Nadeem R, Jilani MI (2012) Pb(II) removal from wastewater using pomegranate waste biomass. Int J Chem Biochem Sci $1: 24-29$

Azreen I, Lija Y, Zahrim AY (2017) Ammonia nitrogen removal from aqueous solution by local agricultural wastes. IOP Conf Ser Mater Sci Eng 206:012077. https://doi.org/10.1088/1757899X/206/1/012077

Ben-Ali S, Jaouali I, Souissi-Najar S, Ouederni A (2017) Characterization and adsorption capacity of raw pomegranate peel biosorbent for copper removal. J Clean Prod 142:3809-3821. https://doi. org/10.1016/j.jclepro.2016.10.081

Bhatnagar A, Minocha AK (2010) Biosorption optimization of nickel removal from water using Punica granatum peel waste. Colloid Surf B 76:544-548. https://doi.org/10.1016/j.colsu rfb.2009.12.016

Bhattacharjee RB, Singh A, Mukhopadhyay SN (2008) Use of nitrogen-fixing bacteria as biofertilizer for non-legumes: prospects and challenges. Appl Microbiol Biotechnol 80:199-209. https://doi. org/10.1007/s00253-008-1567-2

Britto DT, Kronzucker HJ (2002) $\mathrm{NH}_{4}^{+}$toxicity in higher plants: acritical review. J Plant Physiol 159:567-584. https://doi. org/10.1078/0176-1617-0774

Bunnag S, Yamani H (2006) Standard test method for determination of iodine number of activated carbon. Designation: ASTM D 4607-94

Cui X, Hao H, Zhang C, He Z, Yang X (2016) Capacity and mechanisms of ammonium and cadmium sorption on different wetlandplant derived biochars. Sci Total Environ 539:566-575. https:// doi.org/10.1016/j.scitotenv.2015.09.022

Dawodu FA, Akpomie KG (2014) Simultaneous adsorption of Ni(II) and $\mathrm{Mn}$ (II) ions from aqueous solution unto a Nigerian kaolinite clay. J Mater Res Tech 3:129-141. https://doi.org/10.1016/j. jmrt.2014.03.002

De Waal D, Heyns AM, Range K-J, Eglmeier C (1990) Infrared spectra of the ammonium ion in ammonium hexavanadate $\left(\mathrm{NH}_{4}\right)_{2} \mathrm{~V}_{6} \mathrm{O}_{16}$. Spectrochim Acta Part A Mol Spectrosc 46:1649-1657. https:// doi.org/10.1016/0584-8539(90)80277-6

Demiray E, Karatay SE, Dönmez G (2018) Evaluation of pomegranate peel in ethanol production by Saccharomyces cerevisiae and Pichia stipites. Energy 159:988-994. https://doi. org/10.1016/j.energy.2018.06.200

El Nemr A (2009) Potential of pomegranate peel carbon for Cr(VI) removal from wastewater: kinetic and isotherm studies. J Hazard Mater 161:132-141. https://doi.org/10.1016/j.jhazm at.2008.03.093

El-Ashtoukhy E-SZ, Amin NK, Abdelwahab O (2008) Removal of lead (II) and copper (II) from aqueous solution using pomegranate peel as a new adsorbent. Desalination 223:162-173. https://doi. org/10.1016/j.desal.2007.01.206

Fauzia S, Furqani F, Zein R, Munaf E (2015) Adsorption and reaction kinetics of tatrazine by using Annona muricata $\mathrm{L}$ seeds. J Chem Pharm 7(1):573-582
Foo KY, Hameed BH (2010) Insights into the modeling of adsorption isotherm systems. Chem Eng J 156:210. https://doi.org/10.1016/j. cej.2009.09.013

Ghaedi M, Tavallali H, Sharifi M, Nasiri KS, Asghari A (2012) Preparation of low cost activated carbon from Myrtus communis and pomegranate and their efficient application for removal of Congo red from aqueous solution. Spectrochim Acta Part A 86:107-114. https://doi.org/10.1016/j.saa.2011.10.012

Gimbert F, Morin-Crini N, Renault F, Badot P-M, Crini G (2008) Adsorption isotherm models for dye removal by cationized starch-based material in a single component system: error analysis. J Hazard Mater 157:34-46. https://doi.org/10.1016/j.jhazm at.2007.12.072

Gu L, Xu J, Lv L, Liu B, Zhang H, Yu X, Luo Z (2011) Dissolved organic nitrogen (DON) adsorption by using Al-pillared bentonite. Desalination 269(1):206-213. https://doi.org/10.1016/j.desal .2010 .10 .063

Ho Y-S, Mckay G (1999) Pseudo-second order model for sorption processes. Process Biochem 34:451-465. https://doi.org/10.1016/ S0032-9592(98)00112-5

Huang J, Kankanamge NR, Chow C, Welsh DT, Li T, Teasdale PR (2018) Removing ammonium from water and wastewater using cost-effective adsorbents: a review. J Environ Sci-China 63:174197. https://doi.org/10.1016/j.jes.2017.09.009

Ismail ZZ, Hameed BB (2014) Recycling of raw corncob residues as an agricultural waste material for ammonium removal: kinetics, isotherms, and mechanisms. IJEWM 13(3):217-230. https://doi. org/10.1504/IJEWM.2014.059936

Jellali S, Wahab MA, Anane M, Riahi K, Jedidi N (2011) Biosorption characteristics of ammonium from aqueous solutions onto Posidonia oceanica (L.) fibers. Desalination 270(1):40-49. https ://doi.org/10.1016/j.desal.2010.11.018

Karri RR, Sahu NJ (2017) Modeling and optimization by particle swarm embedded neural network for adsorption of zinc (II) by palm kernel shell based activated carbon from aqueous environment. J Environ Manag 206:178-191. https://doi.org/10.1016/j. jenvman.2017.10.026

Karri RR, Sahu NJ, Chimmiri V (2018) Critical review of abatement of ammonia from wastewater. J Mol Liq 261:21-23. https://doi. org/10.1016/j.molliq.2018.03.120

Kotoulas A, Agathou D, Triantaphyllidou IE et al (2019) Zeolite as a potential medium for ammonium recovery and second cheese whey treatment. Water 11(1):136. https://doi.org/10.3390/w1101 0136

Liu H, Dong Y, Liu Y, Wang H (2010) Screening of novel low-cost adsorbents from agricultural residues to remove ammonia nitrogen from aqueous solution. J Hazard Mater 178:1132-1136. https:// doi.org/10.1016/j.jhazmat.2010.01.117

López-Ramón V, Moreno-Castilla C, Rivera-Utrilla J, Radovic LR (2003) Ionic strength effects in aqueous phase adsorption of metal ions on activated carbons. Carbon 41(10):2020-2022. https://doi. org/10.1016/S0008-6223(03)00184-2

Myers D (1999) Adsorption. In: Myers D (ed) Surfaces, interfaces, and colloids, principles and applications. Wiley, New York, pp 199-202

Pagnanelli F, Mainelli S, Vegliò F, Toro L (2003) Heavy metal removal by olive pomace: biosorbent characterization and equilibrium modelling. Chem Eng Sci 58:4709-4717. https://doi. org/10.1016/j.ces.2003.08.001

Ramasamy S, Krishnamoorthy S (2015) Isotherm, kinetic, and thermodynamic studies on Ni (II) removal from aqueous solution by Citrus limettioides seed and its carbon derivative. Environ Prog Sustain Energy 34(5):1384-1395. https://doi.org/10.1002/ep.12134 
Rao AKR, Rehman F (2010) Adsorption of heavy metal ions on pomegranate (Punica granatum) Peel: removal and recovery of $\mathrm{Cr}(\mathrm{VI})$ ions from a multi-metal ion system. Adsorpt Sci Technol 28(3):195. https://doi.org/10.1260/0263-6174.28.3.195

Sheikh MK (2006) The pomegranate. International Book, Lucknow

Sulyman M, Namiesnik J, Gierak A (2017) Low-cost adsorbents derived from agricultural by-products/wastes for enhancing contaminant uptakes from wastewater: a review. Pol J Environ Stud 26(2):479-510. https://doi.org/10.15244/pjoes/66769

Talekar S, Patti AF, Vijayraghavan R, Arora A (2018) Complete utilization of waste pomegranate peels to produce hydrocolloid, punicalagin rich phenolics and hard carbon electrode. ACS Sustain Chem Eng. https://doi.org/10.1021/acssuschemeng.8b03452

Worch E (2012) Adsorption technology in water treatment fundamentals, processes, and modeling. Walter, W. de Gruyter, Berlin

Xu Z, Cai J-g, Pan B-c (2013) Mathematically modeling fixed-bed adsorption in aqueous systems. J Zhejiang Univ Sci A 14(3):155176. https://doi.org/10.1631/jzus.A1300029

Zhong C, Zu Y, Zhao X, Li Y, Ge Y, Wu W, Zhang Y, Li Y, Guo D (2016) Effect of superfine grinding on physicochemical and antioxidant properties of pomegranate peel. Int J Food Sci Technol 51:212-221. https://doi.org/10.1111/ijfs.12982 